\title{
Comunicación a larga distancia: publicidad en México en la emergencia sanitaria, coincidencias y divergencias
}

\section{Distance communication: advertising in México in the health emergency, coincidences and divergences}

Ricardo Ignacio Prado Hurtado*

MostroTown Publicidad

Av. San Jerónimo núm. 1720 , casa 5 ,

C.P. 10000, Lomas Quebradas, Ciudad de México, México

María Dolores Lozano Gutiérrez **

ISU Universidad

25 Sur núm. 702,

C.P. 72160, Col. La Paz, Puebla, México

Editor: Rogelio del Prado Flores

Fecha de recepción: 6 de septiembre de 2021

Fecha de aceptación: 1 de diciembre de 2021 rprado@mostrotown.com.mx

https://orcid.org/0000-0002-4502-428X lolita.lozano@isu.edu.mx https://orcid.org//0000-0002-7451-2346

RESUMEN

La planeación estratégica tiene entre sus funciones la de prever posibles contingencias que puedan presentarse al interior y al exterior de las organizaciones, con la finalidad de estar preparados y contar con las mejores tácticas y herramientas ante una situación de crisis (Sallenave, 2002). Incluso, hay quien piensa que la mayoría de las situaciones adversas que enfrentan las organizaciones son causadas por estas mismas (Costa, 20I8). Hay crisis para las que no hay protocolo alguno, como la crisis sanitaria por Covid-I9. La metodología de este trabajo consiste en una revisión de material publicitario audiovisual presente en internet en México de la fenomenología en torno de la comunicación de

\footnotetext{
* Director General de Servicios Creativos en MostroTown Publicidad, agencia especializada en contramarketing, creatividad y mercadotecnia sociales. Con más de 20 años trabajando en el medio publicitario, ha formado parte de agencias de publicidad nacionales e internacionales trabajando para cuentas en una extensa variedad de categorías de producto y servicio, ha colaborado como docente y conferencista en universidades nacionales.

** Docente. Maestra en Administración de las Tecnologías de la Información y Licenciada en Mercadotecnia con más de diez años de experiencia en las áreas de investigación de mercados, desarrollo de producto y relaciones públicas, así como en el campo docente.
} 
marca frente a la pandemia y una comparativa mediante categorías de análisis. El objetivo de este trabajo de investigación es establecer coincidencias y divergencias entre campañas de comunicación de marca en México y contrastarlas contra un estado del arte construido para este objetivo.

Palabras clave: publicidad con causa, comunicación en pandemia, nuevos tipos de audiencias, reputación digital, comunicación por la salud.

\section{ABSTRACT}

Among its functions, strategic planning is to foresee possible contingencies that may arise inside and outside the organizations, in order to be prepared and have the best tactics and tools in a crisis situation (Sallenave, 2002). There are even those who think that most of the adverse situations that organizations face are caused by them (Costa, 20I8). There are crises for which there is no protocol, such as the health crisis due to COVID-I9. The methodology of this work consists of a review of advertising audiovisual material in Mexico of the phenomenology around brand communication in the face of the pandemic and a comparison through categories of analysis. The objective of this research work is to establish coincidences and divergences between brand communication campaigns in Mexico and contrast them against a state of the art built for this purpose.

Keywords: advertising with a cause, communication in a pandemic, new types of audiences, digital reputation, health communication.

\section{INTRODUCCIÓN}

La crisis de la Covid-ig es un recordatorio que las pandemias han ocurrido en el pasado y continuarán sucediendo en el futuro (Donthu y Gustafsson, 2020), aunque es común escuchar que hay crisis que no se pueden anticipar de ninguna manera, que la Covid-ig fue una contingencia que afectaría al mundo entero en todos sus aspectos no tenía precedente alguno, al menos en Ioo años. El mundo había llegado a un estado de suficiencia tal, que prácticamente había borrado de la memoria la palabra peste, así como las consecuencias de estas a lo largo de la historia. En un siglo caracterizado por el vertiginoso avance de la ciencia y la tecnología parecía impensable que todo se detuviera: las industrias, los gobiernos, los mercados, el trabajo, la educación, en pocas palabras: lo cotidiano. 
El mundo entero tuvo que encontrar la manera de continuar con los recursos que tenía a la mano y así mismo lo hicieron las organizaciones. No obstante, la inercia de una sociedad global que avanzaba a una gran velocidad (Bauman, 2008) la llevó a perder de vista, por un momento, los fenómenos no trascendentales como los de la salud o seguridad. Fenómenos como los relacionados con la publicidad, la comunicación comercial, la mercadotecnia y especialmente las personas a las que van dirigidos sus mensajes.

Las organizaciones nacionales y multinacionales de gran renombre y reputación diseñaron y emitieron de forma casi instantánea campañas (Christie, 2020). Estas se dividieron en varias categorías, desde las que honestamente buscaron transmitir mensajes de aliento, las que buscaron crear conciencia con el fin de promover comunicación que resultara empática, las que buscaron aprovechar el momento para robustecer su presencia de marca y top of mind (Taylor, 2020) e incluso algunas que presumiblemente pudieron haber cometido, intencional o accidentalmente, el error de emplear al momento de shock emocional (Klein, 2008) para buscar promover la venta de sus productos y servicios, lucrando con un momento emocionalmente vulnerable para las personas.

Las personas y en especial los jóvenes aparentemente han encontrado en esta época de incertidumbre momentos para analizar con una mirada crítica la comunicación de las organizaciones que antes validaban por la inmediatez con la que la tenían que procesar, mientras que también logran sintonizar con las marcas que encuentran los códigos correctos (Park, Kim, Lee, Kim, Voyer, Kim, Sung, Gonzalez-Jimenez, Fastoso, Choi y Yoon, 202I). El consumidor (y prosumidor) cada vez es más consciente de que no tienen ninguna obligación para con las organizaciones. El consumidor se encuentra en una posición de poder, pletórica de espacios y plataformas donde puede expresar su opinión con mayor libertad que nunca, acerca de lo que le gusta y lo que no. Hay quien postula que las personas son los nuevos tomadores de decisiones, algo como el nuevo gran director o Chief Executive Officer (CEO) de las organizaciones y parecen dispuestos a todo con tal de demostrarlo (Corona, 20I4).

No obstante, todo parece indicar que estas personas conforman una sociedad que se está hartando cada vez más del ritmo de vida, como asevera Byung-Chul Han (2017), se deja de ser una sociedad disciplinaria para convertirse en una que rinde culto al rendimiento, sujetos emprendedores que rechazan las barreras disciplinarias de los normal o anormal, de esta suerte de obligación con los mercados y de ser el nuevo producto para el ecosistema de los medios digitales así como la nueva moneda de cambio entre estos y las organizaciones nacionales y multinacionales que están dispuestas a pagar grandes sumas de dinero, para saber más acerca de los consumidores y anticiparse de mejor forma a sus deseos; sus filias y fobias, en una suerte de espiral que los lleva cada vez más profundo hacia una feroz batalla por conseguir atención (Lanier, 20I8) o como parecía prever Pierre Bourdieu (1996) cuan- 
do se refería a los medios masivos, en especial la televisión y que parece replicarse en este tiempo en los medios socio digitales:

Hay que tener en cuenta todo lo que debe al hecho de estar situada en un universo de relaciones objetivas entre las diferentes cadenas de televisión que compiten por el mercado en una competencia definida por unas relaciones de fuerza invisibles, pero que pueden ser captadas a través de indicadores como las cuotas de mercado, el peso entre los anunciantes, el capital colectivo de periodistas de prestigio, etcétera. (Bourdieu, 1996, p.58)

Normalizando progresivamente el ritmo de vida frenético cubriéndolo con halo de positividad que se ha vuelto tóxica para esta nueva sociedad, que cada vez tiene más información pero menos conocimiento sobre la realidad del entorno (Han, 20I7), mientras se acapara su atención con más mensajes en cada vez más pantallas, mismas que no son únicamente una vía unilateral de información sino accesos que se encargan de registrar todos nuestros movimientos en la red, clasificarlos y comunicarse entre sí (Lanier, 20I8).

El objetivo de este trabajo de investigación es analizar campañas de publicidad en México en tiempos de la Covid-I9 a partir de categorías de análisis de comunicación publicitaria tomadas del modelo de Soledad Rojas-Rajs y Edgar Jaramillo Soto (2013) y la comunicación para la salud, para dicho efecto se condujo una revisión documental para crear un marco teórico y un estado del arte que pudiera soportar las categorías de análisis que se emplearon en una comparativa compuesta por un corpus de seis campañas de comunicación en México, cuyo objetivo fuera presentar una posición de marca frente a la emergencia mundial por la Covid-I9 donde se clasificaron sus características.

\section{PLANTEAMIENTO DEL PROBLEMA}

La situación de la emergencia sanitaria de la Covid-ıg donde prevalecen noticias acerca de muerte y de riesgos ha motivado a los individuos a buscar seguridad y reducir la incertidumbre (Shin y Kang, 2020), en términos de consumo, los consumidores valoran la autenticidad para reducir la incertidumbre percibida por los consumidores y generando evaluaciones positivas de ellos (Park et al., 202I). No obstante, dado que este fenómeno de la publicidad en tiempos de la pandemia de Covid-ig es relativamente nuevo y a que los investigadores apenas han investigado su impacto de la Covid-ıg en el área es mínimo (Sobande, 2020).

En cifras, en el ámbito de la publicidad a nivel internacional se habla de pérdidas de 26 billones de dólares tan solo en Estados Unidos debido a la pandemia del Covid-ı en 
un contexto que prevé una recuperación aún más lenta que la recesión del 2008 (Vorhaus, 2020). En este contexto de pandemia las marcas han buscado mostrar una imagen solidaria, comunitaria, sensible (Vlad, Sands, Campbell y Pitt, 202I), que conecte con el consumidor que ahora es vulnerable a este acercamiento emocional.

La ruptura de comunicación se identifica entre la publicidad que habla de la Covid-I9 y sus públicos estratégicos, ya que los mensajes podrían estar generando connotaciones no esperadas, más allá de la denotación de los mismos (Barthes, I97I, I993), así como su impacto en la promoción de comportamientos saludables y preventivos, es decir, cuánto aportan en cuestión de calidad informativa de acuerdo con los estudios de Marcelo Royo-Vela y Enrique Bigné (2002) de donde se emplearon algunas categorías de análisis denominadas como novedosas, que pueden ser aplicables a este estudio.

\section{OBJETIVO}

Presentar comparativamente a través de diversas categorías de análisis extraídas de la matriz de análisis para la comunicación en salud (Rojas-Rajs y Jaramillo, 20I3), de los estudios de calidad informativa y su operacionalización, ejemplos de campañas de comunicación en México a propósito de la pandemia por la Covid-I9 para señalar posibles convergencias o divergencias entre los mensajes y, finalmente, proponer otras categorías que podrían generar futuras líneas de investigación alternativas.

Con este objetivo presente, es necesario establecer la diferencia entre los tres diferentes tipos de mensajes analizados que emplean la temática de la Covid-I9: en primer lugar, aquellos que promueven hábitos durante el confinamiento frente a la crisis sanitaria, en segundo lugar los que vinculan las características de sus productos o servicios a las consecuencias o efectos de las disposiciones por la emergencia y finalmente las organizaciones cuyos productos pueden ser empleados como barrera o protección contra al Covid-I9.

\section{ESTADO DE LA CUESTIÓN}

Los estudios en cuanto a la publicidad en la pandemia de la Covid-ig abordan la perspectiva de la adaptación (Taylor, 2020), el tema de la responsabilidad social corporativa (Bergkvist y Taylor, 20I6; Bergkvist y Zhou, 20I9; Schaefer, Terlutter y Diehl, 2020; Taylor, 2020), los medios mayormente utilizados (Corredor-Lanas, Marcos-Recioy Montañés-García, 202I; Del Vasto Bermúdez, 2020) y la creatividad y autenticidad como elementos diferenciadores de las campañas publicitarias en tiempos de Covidı9 (Vlad et al., 202I). 
El estudio de Charles Taylor (2020) plantea que existe una clara necesidad de los publicistas y de las agencias de adaptarse al ambiente que vertiginosamente ha cambiado. Una de las áreas de investigación que se considera en estado de madurez es la responsabilidad social corporativa (Taylor, 2020). Al respecto se ha estudiado la efectividad de varios tipos de apelaciones en temas, por ejemplo la seguridad del consumidor, el bienestar de los empleados, honores a los socorristas, donaciones a la caridad (Schaefer et al., 2020). Otra perspectiva estudia los mensajes, la confianza y la autenticidad de las empresas que se publicitan (Bergkvist y Taylor, 20I6; Bergkvist y Zhou, 20I9).

En España, Patricia Corredor-Lanas, Juan Carlos Marcos-Recio y Fernando Montañés-García (202I) evidencian la prevalencia de los medios digitales y electrónicos sobre los medios impresos. En la misma línea, en Latinoamérica el estudio de Marisol del Vasto Bermúdez (2020) estudia los cambios existentes en la publicidad en Panamá encontrando que las personas pasan más tiempo en las redes sociales por lo que la inversión en medios digitales, optimización de motores de búsqueda (SEO), Email Marketing y Google Ads que generan un ambiente de comunicación y socialización masiva e interactiva están en auge en la pandemia de la Covid-rs.

Una línea de investigación alterna articula el problema de investigación de la publicidad durante la Covid-Ig como un problema de similitud de mensajes y de aburrimiento (Vlad et al., 202I). Los clichés de sin precedentes, extraordinario y estamos juntos en esto han llevado al consumidor al aburrimiento y a considerar los mensajes de agradecimiento y homenaje como una mera explotación (Christie, 2020). Por lo tanto, se sugiere que las marcas solo deben señalar sus aportes cuando sean verdaderamente genuinos y que se evidencie una real diferencia en la situación de crisis (Vlad et al., 202I).

Hablando en general de la comunicación pública, en Rusia, Grigorii L. Tulchinskii (2020) analizó la evolución de las características normativas de valor de la sociedad moderna difundida en los medios de comunicación mostrando que existe una tendencia hacia una transición del predominio de la posverdad a las manifestaciones de la libertad personal como responsabilidad.

\section{FUNDAMENTACIÓN TEÓRICA:}

\section{MARCO TEÓRICO Y CONTEXTUAL}

\section{Mensajes de aliento frente a la Covid-I9}

Byung Chul-Han (2017) menciona en su libro La sociedad del cansancio, en el capítulo dedicado a la violencia neuronal, que cada época tiene padecimientos que la caracterizan, así 
como en un momento las bacterias eran las causantes de la mayoría de los padecimientos, le siguieron los virus, mientras que el sistema inmunológico los identificaba como agentes patógenos y buscaba destruirlos. Sin embargo, los padecimientos de la actualidad son originados por el propio ser social y su exceso de positivismo respecto al estilo de vida y la necesidad de mantenerse ocupado en todo momento. Este fenómeno no solo hace que los padecimientos más frecuentes en la actualidad como la depresión y la ansiedad sean crónicos, sino que los ha vuelto indetectables para el sistema inmunológico ya que es el cerebro el que indica al cuerpo que el exceso de actividades (e información) a las que las personas se exponen diariamente es positivo.

Así que los esfuerzos de las marcas por conectar con las personas podrían considerarse también como impulsos positivos que de acuerdo con Han (2017) están enfermando a las personas:

Las enfermedades neuronales como la depresión, el trastorno por déficit de atención con hiperactividad (TDAH), el trastorno límite de la personalidad (TLP) o el síndrome de desgaste ocupacional (SDO) definen el panorama patológico de comienzos de este siglo. Estas enfermedades no son infecciones, son infartos ocasionados no por la negatividad de lo otro inmunológico, sino por un exceso de positividad. De este modo, se sustraen de cualquier técnica inmunológica destinada a repeler la negatividad de lo extraño. (20I7, p. 6)

Fueron las empresas de comida rápida, alimentos ultraprocesados y bebidas azucaradas algunas de las primeras en manifestarse al inicio de la pandemia con anuncios cargados de creatividad emocional y positivismo haciendo patente que se encuentran atentas de lo que las personas necesitan, que están en esto con ellas, que las comprenden y que sus mensajes tienen una orientación positiva a partir de las recomendaciones internacionales y nacionales (Twitter México, 2020).

En el presente estudio se analizaron campañas audiovisuales con presencia en internet, tanto en páginas especializadas como en medios digitales de alta penetración y frecuencia, por lo que se busca presentar a manera de contraste la visión de autores previos con una posición altamente crítica frente a la publicidad presente en internet, ya que aunque las campañas fueron diseñadas para medios masivos, tienen una presencia permanente en internet donde obtienen un gran volumen de vistas, al margen del marco legal fuera de la red.

A nivel digital es importante tener en consideración una frase que se ha mencionado constantemente y que cada vez toma más fuerza gracias a su difusión reciente en libros, artículos y documentales: "Si no estás pagando, eres tú el producto que están vendiendo" (Martin, 20I3). Señala Jaron Lanier que existen prisioneros de la red que literalmente no 
pueden escapar de ellas debido a factores de adicción psicológica pero que pueden ser ayudados por las demás personas que sí son capaces, con su renuncia a la mayor cantidad posible de productos informáticos en la red, alejándose de las pantallas, dejando de compartir y producir contenidos y datos que permitan a las organizaciones generar modelos detallados de cada persona con la finalidad de vender más.

En la red, el miedo y la ira se manifiestan con mayor frecuencia que fuera de esta, evidentemente en un momento como el de la pandemia esto se intensifica. Estos sentimientos negativos generalmente se manifiestan durante más tiempo en el organismo que los positivos, esto quiere decir que si las personas se sienten molestas, temerosas, tienen más posibilidades de expresarlo en los medios socio digitales por estar continuamente conectadas, independientemente de la sensación de seguridad de comunicarse con una pantalla y no con otra persona (Lanier, 2018).

\section{METODOLOGÍA}

Basado en el estado del arte (marco contextual) y marco teórico que se presenta en las líneas anteriores construido expresamente para sustentar categorías de análisis extraídas de la matriz de análisis para la comunicación por la salud (Rojas-Rajs y Jarillo, 20I3) se incluyen las siguientes categorías (Tabla I).

TABLA 1. CATEGORÍAS DE ANÁLISIS DE PUBLICIDAD EN TIEMPOS DE LA COVID-19

\begin{tabular}{|l|l|}
\hline \multicolumn{1}{|c|}{ CATEGORÍ́ } & \multicolumn{1}{c|}{ DEFINICIÓN OPERACIONAL } \\
\hline Nivel de mensaje & $\begin{array}{l}\text { Nivel 1. Los que promueven hábitos durante el confinamiento } \\
\text { Nivel 2. Los vinculados a los efectos del virus } \\
\text { Nivel 3. Los que pueden prevenir contagios o eliminar el virus }\end{array}$ \\
\hline Eje problemático & Ruptura individual, social o de relaciones abordada por la campaña \\
\hline Riesgo sanitario & $\begin{array}{l}\text { Peligro en el ámbito de la salud, necesidades en salud identificada por la } \\
\text { campaña }\end{array}$ \\
\hline $\begin{array}{l}\text { Comportamientos saludables } \\
\text { promovidos }\end{array}$ & $\begin{array}{l}\text { Conducta individual, social para el cuidado de la salud propuesta por la } \\
\text { campaña }\end{array}$ \\
\hline Mensaje & La recomendación que la campaña promueve \\
\hline
\end{tabular}

FUENTE: ELABORACIÓN PROPIA BASADA EN ROJAS-RAJS Y JARAMILLO (2013). 
Adicionalmente, se creó un corpus de seis piezas pertenecientes a campañas de marca de organizaciones privadas en México que fue analizado mediante un cuadro comparativo que presenta diversas categorías y un análisis de estas basado en los contenidos audiovisuales, gráficos y textuales contenidos. Los criterios de selección fueron que se tratara de campañas de marcas populares en México con mensajes relativos a la crisis sanitaria global provocada por la Covid-I9, desde su inicio y hasta el mes de diciembre de 202I, publicadas en medios masivos y digitales. Mensajes publicitarios que tuvieran por lo menos un aspecto de los tres niveles de mensaje. Que hubieran aparecido en medios durante el periodo de tiempo comprendido entre enero de 2018 y diciembre de 202I. Se emplearon las plataformas digitales especializadas Ads of The World y la plataforma Adlatina, además de la plataforma de más alto tráfico en contenidos audiovisuales YouTube con la finalidad de identificar y seleccionar los anuncios audiovisuales más relevantes para este estudio, a partir de las cuales se generó la propuesta del corpus a analizar:

I. Cinemex, 202I. Covid-pause. Las películas se pusieron en pausa, agosto $202 \mathrm{I}$

2. Sabritas, 2020. \#EstáEnNuestrasManos, noviembre de $202 \mathrm{I}$

3. Uber Eats Latam, \#GraciasPorTuEntrega, noviembre de $202 \mathrm{I}$

4. KFC, 202I. Mamá conference, noviembre de 202I

5. Aeroméxico, 202I. \#OrgulloAeromexico, noviembre de 202I

6. Audi, \#StayHome, diciembre de 202I

\section{RESULTADOS}

A continuación, se presenta la tabla comparativa elaborada con el fin de contrastar y clasificar las campañas de comunicación de marca en México, donde se puede observar los tres niveles de mensaje que emplean como tema central la Covid-I9 (Tabla 2). 
TABLA 2. ANÁLISIS DE CAMPAÑAS CATEGORÍAS PUBLICIDAD EN TIEMPOS DE LA COVID-19

\begin{tabular}{|c|c|c|c|c|c|c|}
\hline MARCA & $\begin{array}{l}\text { NIVEL DE } \\
\text { MENSAJE }\end{array}$ & EJE PROBLEMÁTICO & $\begin{array}{l}\text { RIESGO } \\
\text { SANITARIO QUE } \\
\text { ABORDA LA } \\
\text { CAMPAÑA }\end{array}$ & $\begin{array}{l}\text { COMPORTAMIENTOS } \\
\text { SALUDABLES } \\
\text { PROMOVIDOS } \\
\text { (FUNCIÓN } \\
\text { DISCIPLINARIA) }\end{array}$ & MENSAJE & $\begin{array}{l}\text { CALIDAD INFORMATIVA DEL } \\
\text { MENSAJE }\end{array}$ \\
\hline SABRITAS & $\begin{array}{l}\text { Nivel } 1 . \\
\text { Promueve } \\
\text { hábitos } \\
\text { contra la } \\
\text { Covid-19 }\end{array}$ & $\begin{array}{l}\text { Posible contagio } \\
\text { por higiene } \\
\text { incorrecta de } \\
\text { manos. }\end{array}$ & $\begin{array}{l}\text { Contagio y } \\
\text { enfermedad } \\
\text { por Covid-19 } \\
\text { por higiene } \\
\text { incorrecta. }\end{array}$ & $\begin{array}{l}\text { Lavarse las manos } \\
\text { correctamente. }\end{array}$ & $\begin{array}{l}\text { En Sabritas queremos } \\
\text { reconocer a esas manos } \\
\text { que hoy están echando } \\
\text { una gran mano a } \\
\text { México. } \\
\text { Seguir disfrutando está } \\
\text { en nuestras manos. } \\
\text { Por eso donamos el } \\
\text { equivalente a } 30 \text { mil } \\
\text { jabones y } 70 \text { mil geles } \\
\text { antibacteriales. }\end{array}$ & $\begin{array}{l}\text { En el anuncio no se } \\
\text { menciona si el producto } \\
\text { ayuda en algún aspecto } \\
\text { a la crisis sanitaria. } \\
\text { Se menciona la donación } \\
\text { de productos para la } \\
\text { higiene de manos por } \\
\text { parte de la organización. }\end{array}$ \\
\hline CINEMEX & $\begin{array}{l}\text { Nivel } 2 . \\
\text { Vincula el } \\
\text { servicio a los } \\
\text { efectos de la } \\
\text { Covid-19 }\end{array}$ & $\begin{array}{l}\text { Cierre de salas } \\
\text { de cine por no } \\
\text { ser una actividad } \\
\text { esencial. }\end{array}$ & $\begin{array}{l}\text { Contagio y } \\
\text { enfermedad } \\
\text { por Covid-19 } \\
\text { por } \\
\text { convivencia. }\end{array}$ & $\begin{array}{l}\text { Evitar } \\
\text { concentración de } \\
\text { personas. }\end{array}$ & $\begin{array}{l}\text { Las películas se pusieron } \\
\text { en pausa (...). Nos } \\
\text { veremos pronto, muy } \\
\text { pronto. }\end{array}$ & $\begin{array}{l}\text { En el anuncio se } \\
\text { menciona el cierre de } \\
\text { salas como medida } \\
\text { preventiva contra la } \\
\text { Covid-19. En el anuncio } \\
\text { no se menciona si } \\
\text { el servicio ayuda en } \\
\text { algún aspecto a la crisis } \\
\text { sanitaria ya que el cierre } \\
\text { fue obligatorio. }\end{array}$ \\
\hline $\begin{array}{l}\text { UBER EATS } \\
\text { LATAM }\end{array}$ & $\begin{array}{l}\text { Nivel } 2 . \\
\text { Vincula el } \\
\text { servicio a los } \\
\text { efectos de la } \\
\text { Covid-19 }\end{array}$ & $\begin{array}{l}\text { Confinamiento } \\
\text { frente a personas } \\
\text { que siguen } \\
\text { trabajando. }\end{array}$ & $\begin{array}{l}\text { Contagio y } \\
\text { enfermedad } \\
\text { por Covid-19 } \\
\text { por actividades } \\
\text { en el exterior. }\end{array}$ & $\begin{array}{l}\text { Mantener el } \\
\text { confinamiento. }\end{array}$ & $\begin{array}{l}\text { Demos un mensaje } \\
\text { de aliento y también } \\
\text { de agradecimiento. } \\
\text { Déjales un mensaje en } \\
\text { tu puerta. Gracias por tu } \\
\text { entrega. }\end{array}$ & $\begin{array}{l}\text { En el anuncio se } \\
\text { menciona que el servicio } \\
\text { permite quedarse en } \\
\text { casa como medida } \\
\text { preventiva contra la } \\
\text { Covid-19. }\end{array}$ \\
\hline KFC & $\begin{array}{l}\text { Nivel } 2 . \\
\text { Vincula el } \\
\text { servicio a los } \\
\text { efectos de la } \\
\text { Covid-19 }\end{array}$ & $\begin{array}{l}\text { Confinamiento } \\
\text { en días feriados } \\
\text { que generan } \\
\text { reuniones. }\end{array}$ & $\begin{array}{l}\text { Contagio y } \\
\text { enfermedad } \\
\text { por Covid-19 } \\
\text { por } \\
\text { convivencia. }\end{array}$ & $\begin{array}{l}\text { Mantener el } \\
\text { confinamiento. }\end{array}$ & $\begin{array}{l}\text { Mi mamá hace de todo. } \\
\text { Necesitas tiempo para ti } \\
\text { y yo no te dejo. Festeja a } \\
\text { mamá en casa. }\end{array}$ & $\begin{array}{l}\text { En el anuncio se } \\
\text { menciona que el servicio } \\
\text { permite quedarse en } \\
\text { casa como medida } \\
\text { preventiva contra la } \\
\text { Covid-19. }\end{array}$ \\
\hline AEROMÉXICO & $\begin{array}{l}\text { Nivel } 3 . \\
\text { El servicio } \\
\text { ayuda a } \\
\text { eliminar la } \\
\text { Covid-19 }\end{array}$ & $\begin{array}{l}\text { Riesgos a la } \\
\text { salud en espacios } \\
\text { cerrados y con } \\
\text { alto tráfico de } \\
\text { personas. }\end{array}$ & $\begin{array}{l}\text { Contagio y } \\
\text { enfermedad } \\
\text { por Covid-19 } \\
\text { por } \\
\text { convivencia. }\end{array}$ & $\begin{array}{l}\text { Continuar con } \\
\text { actividades } \\
\text { fundamentales } \\
\text { con medidas } \\
\text { que eliminan la } \\
\text { Covid-19. }\end{array}$ & $\begin{array}{l}\text { Tu seguridad es primero. } \\
\text { Sistema de gestión de } \\
\text { higiene. }\end{array}$ & $\begin{array}{l}\text { En el anuncio se } \\
\text { menciona que existen } \\
\text { protocolos de seguridad } \\
\text { e higiene que eliminan } \\
\text { el } 99.99 \text { de virus y } \\
\text { bacterias en los espacios } \\
\text { del servicio. }\end{array}$ \\
\hline AUDI & $\begin{array}{l}\text { Nivel } 2 . \\
\text { Vincula el } \\
\text { servicio a los } \\
\text { efectos de la } \\
\text { Covid-19 }\end{array}$ & $\begin{array}{l}\text { Riesgos a la } \\
\text { salud por romper } \\
\text { el confinamiento. }\end{array}$ & $\begin{array}{l}\text { Contagio y } \\
\text { enfermedad } \\
\text { por Covid-19 } \\
\text { por } \\
\text { convivencia. }\end{array}$ & $\begin{array}{l}\text { Mantener el } \\
\text { confinamiento. }\end{array}$ & $\begin{array}{l}\text { Stay Home. Audi } \\
\text { Together. }\end{array}$ & $\begin{array}{l}\text { En el anuncio no se } \\
\text { menciona si el producto } \\
\text { ayuda en algún aspecto } \\
\text { a la crisis sanitaria. } \\
\text { Se menciona quedarse } \\
\text { en casa e implícitamente } \\
\text { no usar el auto para salir. }\end{array}$ \\
\hline
\end{tabular}

FUENTE: ELABORACIÓN PROPIA BASADA EN CATEGORÍAS DE LA MATRIZ DE ANÁLISIS DE CATEGORÍAS DE COMUNICACIÓN POR LA SALUD DE ROJAS-RAJS Y JARAMILLO, 2013. 
Se encontró que existen convergencias y una constante en el tipo de mensajes analizados, la mayoría de las campañas (Audi, Cinemex, KFC y Uber Eats) presenta mensajes del nivel 2 que vincula el servicio a los efectos de la Covid-I9, lo que podría interpretarse como el tipo de mensaje y connotación de menor profundidad. Este tipo de mensajes presentan coincidencias en la medida de salud propuesta, es decir, invitar a las personas a respetar el confinamiento y evitar en lo posible las actividades en el exterior que puedan convertirse en un riesgo de contagio. Los mensajes restantes pertenecen al nivel I (Sabritas) y 3 (Aeroméxico), respectivamente. El primero promueve los hábitos que pueden evitar el riesgo de contagio por la Covid-ig y proponen un agradecimiento hacia las personas que no pueden dejar de realizar su trabajo ya que sus actividades son primordiales, generando coincidencias con dos mensajes de nivel 2 en que la propuesta informativa de la publicidad es proponer un reconocimiento a quienes deben continuar con su trabajo para el bien común, como es el caso de los repartidores que permiten quedarse en casa evitando que las personas tengan que salir, el reconocimiento a las personas, específicamente a sus manos, que han permitido que el mundo se siga moviendo y finalmente a las mamás que han tenido que desempeñar más actividades, adquirir competencias sobre el proceso dentro de una curva de aprendizaje, que se suman a las que ya realizan y que no son remuneradas.

Cinco de los mensajes de forma explícita o implícita recomiendan quedarse en confinamiento como primera medida preventiva, mientras que el anuncio restante (Aeroméxico) pone énfasis en que se puede seguir viajando, pero ahora con nuevos niveles de seguridad. La constante en los mensajes es quedarse en casa mientras que de forma diferenciada los demás anuncios mencionan medidas como la higiene de manos, un tema que no se aborda con frecuencia. Todas las campañas proponen una función disciplinaria desde el punto de vista de la comunicación por la salud (Rojas-Rajs y Jarillo, 20I3). Es importante mencionar que las seis campañas emplean como tema principal el contexto de pandemia por la Covid-r 9 y sus efectos, por lo que se les puede considerar como comunicación por la salud, no obstante, atendiendo al análisis de categorías de comunicación de salud en el caso de la campaña de reconocimiento a las manos de la marca Sabritas se pueden encontrar tres mensajes en pro de la salud: lavarse las manos de forma adecuada, promover el reconocimiento a la minoría que trabaja para que la mayoría pueda continuar con el cuidado y la prevención y finalmente la comunicación de un programa de responsabilidad social que dona productos para la higiene adecuada de las manos, convirtiéndose en el más completo y por ende el que presenta mayor calidad informativa. No obstante, si se toma en cuenta a Demsar, Sands, Campbell y Pitt (202I), dichos mensajes no significan un aporte verdaderamente sustancial al ámbito de la comunicación por la salud en sus tres niveles, probablemente en la economía y la generación de empleos mas no con propuestas para el cuidado de la salud de manera diferenciada, 
ya que todos se basan en mensajes que se repiten constantemente y, desafortunadamente se han vuelto parte del paisaje publicitario.

A nivel coincidente todas las campañas apelan al sentido de responsabilidad de cada individuo en su libertad y en su consciencia en línea con lo establecido por Feenstra (20I4) y Tulchinskii (2020). Si bien la literatura identifica que cronológicamente en la publicidad se fue apelando a la responsabilidad individual conforme fue transcurriendo mayor tiempo en la pandemia de la Covid-ı9 (Tulchinskii, 2020), en las campañas analizadas se observa este principio desde campañas generadas a inicios de la pandemia. En cuanto al halo de positividad presente en las comunicaciones del mundo actual, según Han (20I7) se ve ejemplificado en las campañas de Aeroméxico y Sabritas, donde se ha encontrado una manera de dar la vuelta a la emergencia sanitaria en favor del consumidor y de la organización.

Todas las marcas de las campañas analizadas aprovecharon la eventualidad de la Covid-rg como narrativa para hacerse presente buscando establecer un vínculo lógico con el producto o servicio ofrecido por sus marcas; como dice Bourdieu (1996), la competencia por el mercado se mide por el peso entre los anunciantes que en el ámbito digital remite a estar presente y vigente de acuerdo con lo que está dando de qué hablar en el contexto mediático, es decir adaptarse al contexto (Taylor, 2020). En este sentido, se identifica un esfuerzo de las marcas para construir en sus campañas mensajes forzando en algunos casos el beneficio o aporte de sus decisiones comerciales con el ánimo de destacar su lado responsable y por ende para favorecer una reputación positiva hacia sus marcas mediante la responsabilidad social corporativa, el mejor ejemplo en este sentido sería la campaña de Cinemex que aprovecha el tener que acatar una exigencia gubernamental y la presenta como una decisión de responsabilidad propuesta por la organización (Taylor, 2020).

\section{CONCLUSIONES}

La pandemia de la Covid-ı 9 no fue impedimento para que las marcas continuaran haciéndose presente en los medios no solo para buscar vender, sino para incluso dar de qué hablar y generar presencia de marca y reputación positiva. Si bien las campañas analizadas se ubican dentro del rubro de la comunicación de salud por abordar aspectos relacionados con ella, no es posible afirmar que toda la comunicación de salud tiene el cometido de generar mensajes que incidan en la generación de comportamientos saludables situándose en aspectos meramente informativos o persuasivos.

Desde un aspecto social, este tipo de publicidad puede ser considerada por los anunciantes y sus públicos como una poderosa señal de empatía,incluso se planean con una intención 
racional connotativa que los lleve a la reflexión, pero empleando también denotaciones que tienen como objetivo conectar emocionalmente al instante mediante el uso de elementos creativos, textuales, auditivos y visuales de alto impacto. No obstante, es pertinente mencionar que posiblemente dichos mensajes pueden haber generado molestia en ciertos grupos o personas, mismas que en algunos casos empezaron a actuar de forma reactiva, sarcástica o abiertamente agresiva; contra los esfuerzos de organizaciones que parecían querer mimetizarse con sus consumidores y usuarios a través de mensajes de lo que podría interpretarse como una forma de solidaridad artificial.

Derivado de lo anterior se propone como futura línea de investigación el análisis de las campañas publicitarias, ya no desde la comunicación de salud sino la creación de una categoría denominada publicidad de salud que valide que los mensajes contribuyan al bienestar integral de las personas en el corto y largo plazos. A esta denominación deberían integrarse como parte de estas nuevas líneas conceptos como la congruencia en el mensaje, el valor ético de la propuesta, la evaluación de sus objetivos específicos económicos y de marca contrastados con los efectos comprobables de la campaña sobre el problema. En este sentido, se considera que todos los stakebolders saldrían beneficiados de forma importante, generando un balance entre las propuestas de branding y comunicación mercadológica y los beneficios tangibles reflejados en la salud y la integridad a nivel social.

\section{REFERENCIAS}

Aeroméxico. (202I). \#OrgulloAeroméxico. https://www.adlatina.com/campa\% $\mathrm{C}_{3} \%$ Bras/ad-ageeeuu:-la-ceo-de-youtube-le-responde-a-trump-y-un-spray-de-pimienta-es-lo-m $\% \mathrm{C}_{3} \%$ Ais-vendido-en-amazon

Audi. (202I). \#StayHome. https://www.adlatina.com/campa\%C3\%Bras/acmcgarrybowen.com

Barthes, R. (197I). Elementos de semiología. Alberto Corazón.

Barthes, R. (1993). La aventura semiologica. Paidós.

Bauman, Z. (2008). La Sociedad Sitiada. Fondo de Cultura Económica.

Bergkvist,L.y Taylor, C.(2016).Leveraged marketing communications: A framework for explaining the effects of secondary Brand associations. AMS Review, 3-4, 157-75. https://doi.org/I0.I007/ sizi62-0I6-008I-4

Bergkvist, L. y Zhou, K. Q. (2019). Cause-related marketing persuasion research: An integrated framework and directions for further research. International Fournal of Advertising, 38(I), 5-25. https://doi.org/I0.I080/02650487.2018.1452397

Bourdieu, P. (1996). Sobre la Televisión. Anagrama.

Byung-Chul, H. (2017). La Sociedad del Cansancio. Herder. 
Christie, D. (2020, I9 de mayo). Sameness, exploitation sets in for COVID-I9 ads, study says. https://www.marketingdive.com/news/sameness-exploitation-sets-in-for-covid-I9-adsstudy-says/578202/

Cinemex. (202I, 2I de julio). Covid-pause. https://www.adsoftheworld.com/media/film/cinemex covidpause

Corona, A. (2014, 4 de marzo). El nuevo CEO de tu empresa: el consumidor. https://www.informabtl.com/el-nuevo-ceo-de-tu-empresa-el-consumidor/

Corredor-Lanas, P., Marcos-Recio, J.-C. y Montañés-García, F. (202I). Impacto de la pandemia Covid-I9 sobre la publicidad. España como laboratorio de la crisis y de las tendencias comunicativas. Profesional de la información, 3, e300313. https://doi.org/10.3145/epi.2021.may.I3

Costa, J. (2012, I9 de marzo). Joan Costa: El error de las empresas es su incongruencia. Diario Gestión. https://www.youtube.com/watch?v=7OgeGiEtlLg

Del Vasto, M. (2020). Publicidad en plataformas y estrategias digitales alternativas al COVID I9. FAECO SAPIENS, 28-43. http://portal.amelica.org/ameli/jatsRepo/22I/22II95I002/html/ index.html

Donthu, N. y Gustafsson, A. (2020). Effects of COVID-ig on business and research. Fournal of business research, II7, 284-289. https://doi.org/10.1016/j.jbusres.2020.06.008

Feenstra, R. (20I4). Ética de la publicidad. Retos en la era digital. Dykinson.

Klein, N. (2008). The Shock Doctrine: The Rise of Disaster Capitalism. Penguin.

KFC. (202I). Mamá Conference. https://www.adlatina.com $/$ campa $\% \mathrm{C}_{3} \%$ Bras $/ \mathrm{mam}_{3} \mathrm{C}_{3} \% \mathrm{AI}_{\mathrm{I}-\mathrm{con}-}$ ference

Lanier, J. (2018). Diez Razones para borrar tus redes sociales de inmediato. Penguin Random House.

Martin, A. (2013). Si no estás pagando, eres tú el producto que están vendiendo. Novática.

Park, J., Kim, J., Lee, D. C., Kim, S. S., Voyer, B. G., Kim, C., Sung, B, Gonzalez-Jimenez, H.,Fastoso, F., Choi, Y.,Yoon, S. (202I). The impact of COVID-I9 on consumer evaluation of authentic advertising messages. Psychology and Marketing. https://doi.org/I0.1002/mar.21574

Rojas-Rajs, S. y Jarillo, E. (20I3). Comunicación para la salud y estilos de vida saludables: aportes para la reflexión desde la salud colectiva. Interface-Comunicação, Saúde, Educação, 587-599. https://doi.org/IO.I590/Si4I4-32832013000300008

Royo-Vela, M. y Bigné, E. (2002). Una propuesta consensuada de las categorias para el analisis informativo de la publicidad. Revista Europea de Direcciony Economia de la Empresa. https://dialnet. unirioja.es/servlet/articulo? codigo $=253885$

Sabritas. (2020). \#Estáennuestrasmanos. https://www.adlatina.com/campa\%C3\%Bias/sabritas$\% \mathrm{C}_{2} \% \mathrm{AE}$-estaennuestrasmanos

Sallenave, J. P. (2002). Gerencia y planeación estratégica. Norma.

Schaefer, S., Terlutter, R. y Diehl., S. (2020). Talking about CSR matters: Employees' perception of and reaction to their company's CSR communication in four different CSR domains. International Fournal of Advertising, 39(2), I9I-2 I2. https://doi.org/I0.1080/02650487.2019.1593736 
Shin, H. y Kang, J. (2020). Reducing perceived health risk to attract hotel customers in the COVID-I9 pandemic era: Focused on technology innovation for social distancing and cleanliness. International Fournal of Hospitality Management, 9I, eIO2664. https://doi.org/IO.IOI6/j. ijhm.2020.102664

Sobande, F. (2020). 'We're all in this together': Commodified notions of connection, care and community in brand responses to COVID-19. European Fournal of Cultural Studies, 23(6), I033-I337. https://doi.org/IO.II77/1367549420932294

Taylor, C. R. (2020). Advertising and COVID-19. International Fournal of Advertising, 39(5), 587 589. https://doi.org/I0.1080/02650487.2020.1774131

Tulchinskii, G. L. (2020). The dynamics of public discourse during the coronavirus pandemic: a request for responsibility. Russian Fournal of Communication, I2 (3), 193-2I4. https://doi.org/IO $.1080 / 19409419.2020 .1838875$

Twitter México. (2020, 17 de diciembre). Best of Tweet Mexico 2020. https://blog.twitter.com/ es_la/topics/company/2020/best-of-tweets-mexico-2020

Uber Eats Latam. (202I). \#Graciasportuentreg. https://www.adlatina.com/campa\% $\mathrm{C}_{3} \%$ Bias/graciasportuentrega

Vlad, D., Sands, S., Campbell, C.y Pitt, L. (202I). “Unprecedented," “extraordinary,” and “we're all in this together": Does advertising really need to be so tedious in challenging times? Marketing హ゙Techonology, 64(4), 415-424. https://doi.org/I0.I016/j.bushor.2021.02.007

Vorhaus, M. (2020). COVID-I9 represents the biggest challenge to media advertising expeditures ever. https://www.forbes.com/sites/mikevorhaus/2020/04/27/covid-I9-represents-thebiggest-challenge-to-media-advertising-expenditures-ever/

Esta obra está bajo Licencia Creative Commons Atribución-NoComercial-SinDerivadas 4.o Internacional. 